\title{
Keunggulan Bank Pembiayaan Rakyat Syariah "Amanah Ummah" Dalam Penerapan Fatwa Dewan Syariah Nasional dan Peraturan Otoritas Jasa Keuangan
}

\author{
Andi Muhammad Asrun', Abdu Rahmat Rosyadi' ${ }^{2}$, Agus Satory ${ }^{3}$, \\ Yennie K. Milono ${ }^{4}$, Ridwan Malik ${ }^{5}$ \\ Program Pascasarjana Ilmu Hukum Universitas Pakuan-Bogor \\ https://doi.org/10.32507/mizan.v4i1.594
}

\begin{abstract}
Islamic People's Financing Bank (BPRS) is a bank that conducts business activities based on sharia principles which in its activities do not provide services in payment traffic. The development trend of BPRS since the enactment of Islamic banking law continues to increase. All BPRS activities are obliged to apply sharia principles which are stated by the National Sharia Board of the Indonesian Ulema Council (DSN-MUI). After the Financial Services Authority (OJK) was formed there is now a change in regulation that the enactment of the DSN-MUI fatwa must be included in the Financial Services Authority Regulation (POJK). Sharia banking problems that arise at this time generally occur in Sharia Commercial Banks (BUS), Sharia Business Units (UUS), as well as in Islamic People's Financing Banks (BPRS) in terms of applying sharia principles that are not consistent there is still not yet under the fatwa DSN-MUI which has become OJK regulations. Research on the BPRS Amanah Ummah was conducted on capital assets. This research was conducted with a juridical-normative approach that places the laws and regulations as the object of research originating from primary, secondary, and tertiary laws. Primary data were obtained through direct interviews with BPRS Amanah Ummah. While secondary data obtained from legislation, books, journals, and other documents. The results of the study concluded that the BPRS Amanah Ummah financing products have consistently applied the principles of Islamic banking based on the DSN-MUI Fatwa.
\end{abstract}

Keywords: Excellence, Implementation, SRB, DSN Fatwa, OJK

\section{Abstrak}

Bank Pembiayaan Rakyat Syariah (BPRS) adalah bank yang melaksanakan kegiatan usaha berdasarkan prinsip syariah yang dalam kegiatannya tidak memberikan jasa dalam lalu lintas pembayaran. Tren perkembangan BPRS sejak diberlakukan undang-undang perbankan syariah terus meningkat. Seluruh kegiatan BPRS wajib menerapkan prinsipprinsip syariah yang difatwakan oleh Dewan Syariah Nasional Majelis Ulama Indonesia

\footnotetext{
* Naskah diterima: 11 Januari 2020, direvisi: 18 Maret 2020, disetujui untuk diterbitkan: 4 Juni 2020.

${ }_{1}$ Andi Muhammad Asrun adalah peneliti pada Program Pascasarjana Ilmu Hukum Universitas Pakuan-Bogor. Jalan Pakuan PO BOX 452 Bogor. e-mail: pasca@unpak.ac.id www.pasca.unpak.ac.id

2 Abdu Rahmat Rosyadi adalah peneliti pada Program Pascasarjana Ilmu Hukum Universitas Pakuan-Bogor. Jalan Pakuan PO BOX 452 Bogor. e-mail: pasca@unpak.ac.id www.pasca.unpak.ac.id

3 Agus Satory adalah peneliti pada Program Pascasarjana Ilmu Hukum Universitas PakuanBogor. Jalan Pakuan PO BOX 452 Bogor. e-mail: pasca@unpak.ac.id www.pasca.unpak.ac.id

4 Yennie K. Milono adalah peneliti pada Program Pascasarjana Ilmu Hukum Universitas Pakuan-Bogor. Jalan Pakuan PO BOX 452 Bogor. e-mail: pasca@unpak.ac.id www.pasca.unpak.ac.id

${ }^{5}$ Ridwan Malik adalah peneliti pada Program Pascasarjana Ilmu Hukum Universitas PakuanBogor. Jalan Pakuan PO BOX 452 Bogor. e-mail: pasca@unpak.ac.id www.pasca.unpak.ac.id
} 


\begin{abstract}
(DSN-MUI). Setelah dibentuk Otoritas Jasa Keuangan (OJK) saat ini telah terjadi perubahan regulasi bahwa pemberlakuan fatwa DSN-MUI harus masuk ke dalam Peraturan Otoritas Jasa Keuangan (P-OJK). Permasalahan perbankan syariah yang timbul saat ini secara umum terjadi pada Bank Umum Syariah (BUS), Unit Usaha Syariah (UUS), maupun pada Bank Pembiayaan Rakyat Syariah (BPRS) dalam hal penerapan prinsip-prinsip syariah yang belum konsisten, bahkan masih ada yang belum sesuai dengan fatwa DSN-MUI yang sudah menjadi peraturan OJK. Penelitian terhadap BPRS Amanah Ummah ini dilakukan pada aset permodalan. Penelitian ini dilakukan dengan pendekatan yuridis-normatif yang menempatkan peraturan perundang-undangan sebagai objek penelitian yang bersumber dari hukum primer, sekunder, dan tersier. Data primer diperoleh melalui wawancara langsung dengan pihak BPRS Amanah Ummah. Sedangkan data sekunder diperoleh dari peraturan perundang-undangan, buku, jurnal, dan dokumen lainnya. Hasil penelitian menyimpulkan bahwa dari produk-produk pembiayaan BPRS Amanah Ummah telah menerapkan prinsip-prinsip perbankan syariah berdasarkan Fatwa DSN-MUI secara konsisten.
\end{abstract}

Kata Kunci: Keunggulan, Penerapan, BPRS, Fatwa DSN, OJK

\title{
A. PENDAHULUAN
}

Berdasarkan Undang-Undang Nomor 21 Tahun 2008 tentang Perbankan Syariah, kelembagaan Bank Pembiayaan Rakyat Syariah (BPRS) semakin diperkuat dengan landasan hukum. Hal yang cukup menarik adalah sejak undang-undang ini diberlakukan istilah "perkreditan" dalam BPRS (Bank Perkreditan Rakyat Syariah) diganti dengan "pembiayaan". ${ }^{6}$ Berdasarkan undang-undang tersebut pihak-pihak yang akan melakukan kegiatan usaha perbankan terlebih dahulu wajib memperoleh izin usaha sebagai bank syariah, Unit Usaha Syariah (UUS), dan/atau Bank Pembiayaan Rakyat Syariah (BPRS) dari Bank Indonesia. Sedangkan bank umum konvensional yang melakukan kegiatan usaha berdasarkan prinsip syariah wajib membuka UUS di kantor pusat bank dengan izin Bank Indonesia. Untuk menutup kemungkinan adanya pihak-pihak yang tidak meminta izin akibat hanya melakukan kegiatan penghimpunan dana masyarakat saja, maka diatur pula ketentuan larangan atas setiap pihak untuk melakukan kegiatan dimaksud tanpa izin dari Bank Indonesia.

Selain mendirikan bank syariah atau UUS baru, pihak-pihak yang ingin melakukan kegiatan usaha perbankan syariah dapat melakukan pengubahan (konversi) bank konvensional menjadi bank syariah. Pengubahan dari bank syariah menjadi bank konvensional merupakan hal yang dilarang dalam undang-undang ini. Di samping itu, pendirian Bank Umum Syariah (BUS) baru dapat dilakukan dengan cara pemisahan (spin off) UUS dari induknya. Bagi UUS yang nilai asetnya telah mencapai 50\% dari total aset bank induknya atau 15 tahun sejak berlakunya undangundang ini maka wajib melakukan pemisahan UUS menjadi BUS. Dengan demikian berdasarkan ketentuan ini seluruh UUS pada tahun 2003 sudah tidak ada di industri perbankan syariah nasional. Pada tahun 2003 UUS dapat berubah menjadi BUS. Hal ini tentu bergantung pada kemampuan bank syariah tersebut.

BPRS merupakan badan usaha yang setara dengan Bank Perkreditan Rakyat (BPR) dengan bentuk hukum perseroan terbatas, perusahaan daerah, atau koperasi.

\footnotetext{
${ }^{6}$ Bank Indonesia. 2016. Perjalanan Perbankan Syariah di Indonesia, Jakarta: BNI, hlm. 104.
} 
Tren perkembangan BPRS sejak diberlakukan undang-undang perbankan syariah terus meningkat. Pada tahun 2005 terdapat 81 BPRS sedangkan pada tahun 2013 meningkat pesat menjadi 138 BPRS. Kegiatan BPRS meliputi: 1) menghimpun dana dari masyarakat; 2) menyalurkan dana kepada masyarakat; 3) melakukan kegiatan usaha BPRS; 4) mentransfer; dan 5) menyediakan produk bank syariah.

Seluruh kegiatan usaha bank syariah dan UUS didasarkan pada prinsip syariah dengan implikasinya harus selalu sesuai dengan Fatwa Dewan Syariah Nasional Majelis Ulama Indonesia (DSN-MUI). Juga karena dalam prinsip syariah memiliki berbagai variasi akad yang akan menimbulkan variasi produk yang lebih banyak dibandingkan produk bank konvensional. Pada sisi lain, kegiatan penyaluran dana berdasarkan prinsip syariah harus dilakukan secara hati-hati melalui penilaian secara seksama, agar bank syariah atau UUS memiliki kesesuaian dengan prinsip syariah.

Permasalahan perbankan syariah yang timbul saat ini secara umum terjadi pada BUS, UUS, maupun pada BPRS dalam hal penerapan prinsip-prinsip syariah yang belum konsisten, bahkan masih ada yang belum sesuai dengan fatwa DSN-MUI yang sudah menjadi peraturan Otoritas Jasa Keuangan (OJK). Para pelaku perbankan syariah terutama yang berasal dari perbankan konvensional masih mengikuti tren bisnis di sektor perbankan syariah tetapi belum sepenuhnya menerapkan prinsipprinsip syariah secara nyata. Demikian juga hal ini diasumsikan berlaku pada BPRS yang jumlahnya semakin meningkat namun dalam penerapan prinsip-prinsip syariah berdasarkan fatwa DSN-MUI dan Peraturan Otoritas Jasa Keuanagan (POJK) perlu dilakukan penelitian secara komprehensif.

Penelitian ini dilakukan di BPRS Amanah Ummah sebagai salah satu BPRS lokal yang berlokasi di Leuwiliang, Kabupaten Bogor dan menjadi salah satu BPRS unggul di Indonesia dalam mempromosikan produk-produk perbankannya dengan penerapan prinsip-prinsip syariah. Penelitian difokuskan pada: (1) Penerapan fatwa DSN-MUI dan POJK dalam produk-produk pembiayaan syariah BPRS Amanah Ummah; dan (2) Kriteria BPRS Amanah Ummah sebagai BPRS unggul di Indonesia.

\section{B. METODE PENELITIAN}

Penelitian terhadap BPRS ini, menggunakan pendekatan yuridis-normatif yang menempatkan peraturan perundang-undangan sebagai obyek penelitian. Penelitian yuridis-normatif disebut juga dengan istilah penelitian doktrinal yang meneliti sumber pustaka atau dokumen hukum sebagai obyek kajian atau sasaran penelitian. Sumber hukum primer perbankan syariah yang menjadi obyek penelitian adalah: (1) UndangUndang Nomor 10 Tahun 1998 Tentang Perubahan Atas Undang-Undang Nomor 7 Tahun 1992 Tentang Perbankan; (2) Undang-Undang Nomor 21 Tahun 2008 Tentang Perbankan Syariah; (3) Undang-Undang Nomor 21 Tahun 2011 Tentang Otoritas Jasa Keuangan; (4) Surat Edaran Otoritas Jasa Keuangan Nomor 37/SEOJK.03/2015 tentang Produk dan Aktivitas Bank Pembiayaan Rakyat Syariah; (5) Keputusan DSN-MUI Nomor 1 Tahun 2000 tentang Pedoman Dasar Dewan Syariah Nasional Majelis Ulama Indonesia (PD DSN-MUI); dan (6) Keputusan DSN-MUI Nomor 3 Tahun 2000 tentang 
Petunjuk Pelaksanaan Penetapan Anggota Dewan Pengawas Syariah Pada Lembaga Keuangan Syariah.

Dari peraturan perundang-undangan tersebut maka fokus penelitian yang berkaitan dengan produk-produk pembiayaan BPRS Amanah Ummah meliputi delapan Fatwa DSN-MUI yaitu: (1) DSN Nomor 4/MUI/IV/2000 (Murabahah); (2) DSN Nomor 5/ MUI/IV/2000 (Salam); (3) DSN Nomor 6/MUI/IV/2000 (Istishna); (4) DSN Nomor 7/MUI/IV/2000 (Mudharabah/Qiradh); (5) DSN Nomor 8/ MUI/IV/2000 (Musyarakah); (6) DSN Nomor 19/ MUI/IV/2001 (Qardh); (7) DSN Nomor 26/ MUI/III/2002 (Qardh); (8) DSN Nomor 27/ MUI/III/2002 (ijarah, ijarah muntahiya bit tamlik, ijarah multi jasa).

Dokumen hukum sekunder adalah hukum dalam bentuk buku-buku hukum dan buku-buku non-hukum yang berkaitan dengan penelitian ini maupun karya-karya tulis di bidang hukum yang dalam bentuk artikel yang terbit pada jurnal-jurnal hukum. Hukum sekunder berfungsi untuk menjelaskan terhadap bahan-bahan hukum primer. Sedangkan dokumen hukum tersier adalah hukum berbentuk kamus hukum, ensiklopedi hukum dan lain-lain. Dokumen hukum tersier ini merupakan bahan hukum yang memberikan petunjuk maupun penjelasan terhadap bahan hukum primer dan sekunder.

Analisis data penelitian BPRS bersifat deskriptif-kualitatif untuk menjelaskan tentang penerapan prinsip-prinsip syariah dalam BPRS berdasarkan Fatwa DSN-MUI dan POJK yang berkenaan dengan (1) analisis penerapan prinsip-prinsip syariah terhadap produk-produk BPRS Amanah Ummah berdasarkan Fatwa DSN-MUI dan POJK; dan (2) analisis terhadap kriteria BPRS Amanah Ummah sebagai BPRS Unggul dibandingkan dengan BPRS yang ada di Indonesia.

\section{ANALISIS DAN PEMBAHASAN}

\section{Perbankan Syariah}

Menurut Undang-Undang Nomor 21 Tahun 2008 tentang Perbankan Syariah, definisi bank syariah dinyatakan dalam Pasal 1 angka 1 yaitu: Segala sesuatu yang menyangkut tentang Bank Syariah dan Unit Usaha Syariah, mencakup kelembagaan, kegiatan usaha, serta cara dan proses dalam melaksanakan kegiatan usahanya.

Perbankan syariah pada dasarnya merupakan pengembangan dari konsep ekonomi Islam, terutama dalam bidang keuangan. Bank syariah pada awalnya dikembangkan sebagai suatu respon dari kelompok ekonomi dan praktisi perbankan muslim yang berupaya mengakomodasi desakan dari berbagai pihak yang menginginkan agar tersedia jasa transaksi keuangan yang dilaksanakan sejalan dengan nilai moral dan prinsip-prinsip syariah Islam. Hal yang paling penting adalah yang berkaitan dengan pelarangan praktek riba, kegiatan maisir (perjudian), gharar 
(ketidakjelasan) dan pelanggaran prinsip keadilan dalam transaksi serta keharusan penyaluran dana investasi pada kegiatan usaha yang etis dan halal secara syariah. ${ }^{7}$

Pengertian prinsip syariah dikemukakan dalam ketentuan Pasal 1 angka 13 Undang-Undang Nomor 7 Tahun 1992 sebagaimana telah diubah dengan UndangUndang Nomor 10 Tahun 1998, yang mengartikan sebagai berikut:

Prinsip syariah adalah aturan perjanjian berdasarkan hukum Islam antara bank dan pihak lain untuk menyimpan dana dan atau pembiayaan kegiatan usaha, atau kegiatan lainnya yang dinyatakan sesuai dengan syariah, antara lain pembiayaan berdasarkan prinsip bagi hasil (mudharabah), pembiayaan berdasarkan prinsip penyertaan modal (musyarakah), prinsip jual beli barang dengan memperoleh keuntungan (murabahah), atau pembiayaan barang modal berdasarkan prinsip sewa murni tanpa pilihan (ijarah), atau dengan adanya pilihan pemindahan kepemilikan atas barang yang disewa dari pihak bank oleh pihak lain (ijarah wa iqtina). ${ }^{8}$

Dalam operasionalnya BPRS tidak diperkenankan untuk membuka produk simpanan giro dan ikut serta dalam lalu lintas pembayaran serta kegiatan valuta asing kecuali penukaran valuta asing. Seluruh kegiatan usaha bank syariah dan UUS pada dasarnya wajib sesuai dengan prinsip syariah dalam Fatwa DSN-MUI. Penuangan prinsip syariah yang telah difatwakan dimaksud ke dalam peraturan Bank Indonesia (PBI), dilakukan oleh Bank Indonesia yang dibantu oleh Komite Perbankan Syariah (KPS). Setelah dibentuk OJK saat ini telah terjadi perubahan regulasi bahwa keberlakuan fatwa DSN-MUI harus masuk ke dalam Peraturan Otoritas Jasa Keuangan (POJK). Selain itu juga bank syariah termasuk BPRS dan UUS wajib membentuk Dewan Pengawas Syariah (DPS) yang bertugas untuk memberikan nasihat dan saran kepada direksi serta mengawasi kegiatan bank agar sesuai dengan prinsip syariah.

\section{Fatwa DSN-MUI}

Dalam sistem hukum Islam, fatwa mempunyai peranan yang sangat dominan dalam memberikan pertimbangan hukum Islam bagi masyarakat sekalipun tidak memiliki kekuatan hukum yang mengikat. Dari segi formalisasi syariat Islam, fatwa dapat dianggap hukum positif di Indonesia maka harus dilegalisasi/diformalisasi oleh suatu badan negara yang diberi kewenangan untuk itu. Misalnya fatwa DSN-MUI yang berkaitan dengan fatwa perbankan syariah harus dilegalisasi oleh OJK yang diberi otoritas oleh negara untuk menjadikan fatwa sebagai hukum positif. ${ }^{9}$

DSN-MUI telah mengeluarkan pedoman dasar tentang bank syariah terkait tentang ditetapkannya keputusan MUI Nomor 01 Tahun 2000 tentang Pedoman Dasar

${ }^{7}$ Indra Fajar Alamsyah. 2013. Penggunaan Produk Perbankan Syariah Yang Menggunakan Akad Wadiah Dihubungkan Dengan Fiqih Muamalah, JURNAL SCIENTICA, UNIBAS, Vol. 1 No.2, Desember 2013, No. ISSN: 2407-2001. Hlm. 31-32.

8 Rahmadi Usman. 2013. Produk dan Akad Perbankan Syariah di Indonesia: Implementasi dan Aspek Hukum, Bandung, Citra Aditia, hlm. 9-11.

9 A. Rahmat Rosyadi. 2006. Formalisasi Syariat Islam dalam Perspektif Tata Hukum Indonesia, Jakarta, Ghalia Indonesia, hlm. 23. 
Dewan Syariah Nasional-Majelis Ulama Indonesia (PD DSN-MUI). Dari pertimbangan yang ditetapkan oleh keputusan pedoman tersebut diantaranya adalah:

a. Bahwa Dewan Syariah Nasional, disingkat dengan nama DSN, dibentuk oleh Majelis Ulama Indonesia dengan tugas mengawasi dan mengarahkan lembagalembaga keuangan syariah untuk mendorong penerapan nilai-nilai ajaran agama Islam dalam kegiatan perekonomian dan keuangan.

b. Bahwa DSN diharapkan dapat berperan secara proaktif dalam menanggapi perkembangan masyarakat Indonesia yang dinamis dalam bidang ekonomi dan keuangan.

c. Bahwa untuk lebih mengefektifkan pelaksanaan tugas dan fungsi DSN, perlu ditetapkan Pedoman Dasar Dewan Syariah Nasional (PD DSN-MUI)

Kepatuhan perbankan syariah sebagaimana diatur dalam Pasal 26 ayat (2) Undang-Undang Nomor 21 Tahun 2008 tentang Perbankan Syariah, dinyatakan bahwa: Prinsip syariah sebagaimana dimaksud pada ayat (1) difatwakan oleh Majelis Ulama Indonesia.

Maka setiap BPRS wajib mengikuti kepatuhan syariah yang dirujuk kepada fatwa DSN-MUI. Segala fatwa yang dikeluarkan oleh DSN menjadi acuan kerja bagi DPS yang memiliki daya laku dan daya ikat yang kuat dalam penerapan prinsip dan aturan syariah di bank syariah. Artinya, fatwa DSN menjadi Peraturan Bank Indonesia dalam aspek kepatuhan syariah adalah untuk menciptakan keseragaman normanorma dalam aspek syariah untuk keseluruhan produk bank. Oleh karena itu, standar utama kepatuhan syariah bagi DPS dalam tataran praktis adalah fatwa DSN yang bersifat mengikat bagi DPS di setiap bank syariah dan menjadikan dasar tindakan hukum bagi pihak-pihak terkait.

Jaminan kepatuhan syariah (shari'a compliance assurance) atas keseluruhan aktivitas bank syariah merupakan hal yang sangat penting bagi nasabah dan masyarakat. Ada beberapa indikator yang dapat digunakan sebagai ukuran secara kualitatif untuk menilai kepatuhan syariah dalam bank syariah, antara lain sebagai berikut:

a. Akad atau kontrak yang digunakan untuk pengumpulan dan penyaluran dana sesuai dengan prinsip-prinsip dan aturan syariah yang berlaku.

b. Dana zakat dihitung dan dibayar serta dikelola sesuai dengan aturan dan prinsip-prinsip syariah.

c. Seluruh transaksi dan aktivitas ekonomi dilaporkan secara wajar sesuai dengan standar akuntasi syariah yang berlaku.

d. Lingkungan kerja dan corporate culture sesuai dengan syariah.

e. Bisnis dan usaha yang dibiayai tidak bertentangan dengan syariah.

f. Terdapat DPS sebagai pengarah syariah atas keseluruhan aktivitas operasional bank syariah.

g. Sumber dana berasal dari sumber dana yang sah dan halal menurut syariah. 


\section{Otoritas Jasa Keuangan}

Selain itu berdasarkan Pasal 34 Undang-Undang Nomor 3 Tahun 2014 tentang perubahan atas Undang-Undang Nomor 23 Tahun 1999 tentang Bank Indonesia, pemerintah diamanatkan membentuk lembaga pengawas sektor jasa keuangan yang independen, selambat-lambatnya akhir tahun 2010 dengan nama Otoritas Jasa Keuangan (OJK). Lembaga ini bertugas mengawasi industri perbankan, asuransi, dana pensiun, pasar modal, modal ventura, dan perusahaan pembiayaan serta badan-badan lain yang menyelenggarakan pengelolaan dana masyarakat. Pada akhirnya yang paling penting itu pengawasannya efektif atau tidak. Prinsipnya, pembentukan OJK agar pengawasan itu menjadi terintegritas dan koordinasinya menjadi lebih mudah sehingga pengawasan dan regulasinya menjadi efektif. ${ }^{10}$

OJK dibentuk dengan tujuan agar keseluruhan kegiatan jasa keuangan di dalam sektor jasa keuangan terselenggara secara teratur, adil, transparan, dan akuntabel serta mewujudkan sistem keuangan yang tumbuh secara berkelanjutan dan stabil, juga mampu melindungi kepentingan konsumen dan masyarakat. Dengan demikian, OJK diharapkan dapat mendukung kepentingan sektor jasa keuangan nasional sehingga mampu meningkatkan daya saing nasional.

Secara kelembagaan, OJK berada diluar pemerintah, yang dimaknai bahwa OJK tidak menjadi bagian dari kekuasaan pemerintah. Namun, tidak menutup kemungkinan adanya unsur-unsur perwakilan pemerintah karena pada hakikatnya OJK merupakan otoritas di sektor keuangan memiliki relasi dan keterkaitan yang kuat dengan otoritas lain, dalam hal ini otoritas fiskal dan moneter. Oleh sebab itu, lembaga ini juga melibatkan keterwakilan unsur-unsur dari kedua otoritas tersebut secara $e x$ officio. ${ }^{11}$

\section{Penerapan Fatwa DSN-MUI dan SEOJK dalam produk-produk pembiayaan syariah BPRS Amanah Ummah}

BPRS Amanah Ummah merupakan bank syariah lokal pertama di LeuwiliangKabupaten Bogor yang beroperasi berdasarkan prinsip syariah. BPRS Amanah Ummah dirintis dan diprakarsai oleh seorang ulama dan cendekiawan muslim serta pejuang kemerdekaan Republik Indonesia yaitu bapak KH. Sholeh Iskandar. Badan hukum PT. BPRS Amanah Ummah untuk kali pertama dibuat dihadapan Notaris Rahayu Beny Sofyan, S.H., yang berlokasi di Bogor. Kemudian izin prinsip diajukan pada bulan Juli 1991 ke Departemen Keuangan Republik Indonesia. Badan hukum disahkan oleh Menteri Kehakiman Nomor C2-1340.HT.01.01TH'92 dan diumumkan dalam Berita Negara Nomor 29 tanggal 10 April 1992. Persetujuan izin prinsip nomor: S.2160/MK.13/1991 yang diperoleh pada tanggal 16 Desember 1991 dari Departemen

10 Adrian Sutedi. 2014. Aspek Hukum Otoritas Jasa Keuangan, Jakarta, Raih Asah Sukses, hlm. 147.

${ }^{11}$ Sri Hartini. 2019. Otoritas Jasa Keuangan: Pengaturan \& Pengawasan dalam Perbankan Syariah Berbasis Fatwa Dewan Syariah Nasional, Bogor: UIKA PRESS, hlm. 134. 
Keuangan Republik Indonesia pada tanggal 11 Juli 1992. Soft opening dan grand opening dilaksanakan pada tanggal 8 Agustus 1992 yang diresmikan oleh Bupati Bogor.

BPRS Amanah Ummah memiliki aset total pada Juli 2019 telah mendekati Rp300 miliar dan juga telah memiliki enam kantor cabang/kas dengan jumlah karyawan sekitar 105 orang. Kantor-kantor tersebut ialah: (1) Kantor Pusat BPRS Amanah Ummah Leuwiliang, Kabupaten Bogor; (2) Kantor Cabang BPRS Amanah Ummah, Kota Bogor; (3) Kantor Cabang BPRS Amanah Ummah, Cicurug-Kabupaten Sukabumi; (4) Kantor Cabang BPRS Amanah Ummah, Cileungsi-Kabupaten Bogor; (5) Kantor Kas BPRS Amanah Ummah, UIKA-Bogor; dan (6) Kantor Kas BPRS Amanah Ummah, Leuwiliang-Kabupaten Bogor. ${ }^{12}$

BPRS Amanah Ummah mengelola tiga jenis kegiatan perbankan yaitu penghimpunan dana, pembiayaan syariah, dan layanan jasa perbankan. Produk penghimpunan dana terdiri atas: (1) tabungan berakad titipan (wadiah) meliputi (a) Tabungan ummah; (b) Tabungan pelajar/simpel Ib Amanah; dan (c) Tabungan haji dan umroh; (2) Deposito berakad bagi-hasil (mudharabah mutlaqah) dengan pemberian bagi hasil yang terbaik untuk nasabah tersedia pilihan jangka waktu: 1, 3, 6 dan 12 bulan dengan jaminan keamanan. Adapun layanan jasa perbankan terdiri atas: (1) PPOB untuk layanan pembayaran rekening (listrik, telepon) token listrik, PDAM, BPJS kesehatan, speedy, top tv, dll (2) Transfer antar bank melalui EDC (electronic data capture).

Dalam penelitian ini yang menjadi fokus pembahasan berkaitan dengan produk-produk pembiayaan syariah yaitu: (1) Berakad jual-beli (murabahah-salamistishna); (2) Berakad bagi-hasil (musyarakah-mudharabah); (3) Berakad sewa, sewa beli dan pengurusan jasa (ijarah, ijarah muntahiya bit tamlik, ijarah multi jasa); (4) Berakad pinjaman talangan dan talangan haji (qardh); (5) Berakad pinjaman beragunan emas atau gadai emas (rahn); dan (6) Berakad pinjaman kebajikan (qardhul hasan).

Penerapan produk-produk pembiayaan syariah di BPRS Amanah Ummah tersebut, menurut keterangan dari Direktur Marketing BPRS Amanah Ummah, Drs. H.M. Abduh Khalid M, M.Si didasarkan pada Fatwa DSN-MUI. Selanjutnya Abduh menjelaskan bahwa Fatwa DSN dimaksud yang dijadikan dasar produk-produk BPRS telah dilegalisasi oleh OJK sebagai POJK dalam bentuk SEOJK Nomor 37/SEOJK.03/2015 tentang Produk dan Aktivitas Bank Pembiayaan Rakyat Syariah.

Realisasi produk-produk pembiayaan syariah BPRS Amanah Ummah yang disalurkan kepada pihak nasabah berdasarkan Fatwa DSN-MUI yang telah dilegalisasi oleh OJK melalui Surat Edaran Nomor 37/SEOJK.03/2015 tentang Produk dan Aktivitas Bank Pembiayaan Rakyat Syariah, seperti dalam tabel D-1.1 sampai dengan D-1.6 di bawah ini.

\section{D-1.1 Akad Jual Beli (Murabahah/Salam/Istishna')}

12 BPRS Amanah Ummah. 2019. Melanjutkan Warisan Perjuangan K.H. Sholeh Iskandar (alm), Bogor, PT. Brosur BPRS Amanah Ummah, hlm. 3. 


\begin{tabular}{|c|c|}
\hline FATWA DSN-MUI & PENERAPAN AKAD PEMBIAYAAN \\
\hline $\begin{array}{l}\text { Fatwa Nomor 04/DSN- } \\
\text { MUI/ IV/2000 tentang } \\
\text { Murahabah }\end{array}$ & $\begin{array}{l}\text { 1. BPRS menyediakan dana atau tagihan untuk transaksi jual beli } \\
\text { barang sebesar harga pokok; } \\
\text { 2. Margin berdasarkan persetujuan atau kesepakatan antara BPRS } \\
\text { dengan nasabah; } \\
\text { 3. Nasabah melunasi pinjaman sebagai kewajibannya; } \\
\text { 4. BPRS menyediakan dana untuk membelikan barang; } \\
\text { 5. Nasabah sebagai pembeli barang yang diinginkan; } \\
\text { 6. Kesepakatan antara BPRS dengan nasabah dituangkan dalam } \\
\text { Akad Murabahah. }\end{array}$ \\
\hline $\begin{array}{l}\text { Fatwa Nomor 05/ DSN- } \\
\text { MUI/ IVI } 2000 \text { tentang Jual } \\
\text { Beli Salam }\end{array}$ & $\begin{array}{l}\text { 1. BPRS menyediakan dana atau tagihan untuk jual beli barang } \\
\text { berdasarkan pesanan nasabah; } \\
\text { 2. Pengiriman barang oleh penjual dan pelunasannya dilakukan oleh } \\
\text { pembeli pada saat akad disepakati. } \\
\text { 3. BPRS dapat bertindak sebagai pembeli dan/atau penjual dalam } \\
\text { suatu transaksi salam. } \\
\text { 4. Dalam hal BPRS sebagai pembeli maka BPRS melakukan } \\
\text { transaksi salam dengan nasabah; } \\
\text { 5. Dalam hal BPRS sebagai penjual maka BPRS akan memesan } \\
\text { kepada pihak ketiga untuk menyediakan barang pesanan dalam } \\
\text { salam paralel. } \\
\text { 6. Kesepakatan antara BPRS dengan nasabah dituangkan dalam } \\
\text { Akad Salam. }\end{array}$ \\
\hline $\begin{array}{l}\text { Fatwa Nomor 06/ DSN- } \\
\text { MUI/ IV/ } 2000 \text { tentang Jual } \\
\text { Beli Istishna' }\end{array}$ & $\begin{array}{l}\text { 1. BPRS menyediakan dana atau tagihan untuk transaksi jual beli } \\
\text { barang dalam bentuk pemesanan/pembuatan barang tertentu; } \\
\text { 2. Pemesanan/pembuatan barang dengan kriteria dan persyaratan } \\
\text { tertentu yang disepakati antara pemesan atau pembeli dan penjual } \\
\text { atau pembuat. } \\
\text { 3. BPRS menyediakan dana atau penjual untuk kegiatan transaksi } \\
\text { istishna' dengan nasabah sebagai pihak pembeli. } \\
\text { 4. Kesepakatan antara BPRS dengan nasabah dituangkan dalam } \\
\text { Akad Istishna'. }\end{array}$ \\
\hline
\end{tabular}

D-1.2 Akad Bagi-Hasil (Musyarakah/Mudharabah)

\begin{tabular}{|l|ll|}
\hline \multicolumn{1}{|c|}{ FATWA DSN-MUI } & \multicolumn{1}{c|}{ PENERAPAN AKAD PEMBIAYAAN } \\
\hline Fatwa Nomor 08/ DSN- & 1. & BPRS menyediakan dana untuk kerjasama usaha tertentu; \\
MUI/ IV/2000 tentang & 2. $\begin{array}{l}\text { Masing-masing pihak memberikan porsi dana dengan ketentuan } \\
\text { Pembiayaan Musyarakah } \\
\text { disepakati; }\end{array}$ & $\begin{array}{l}\text { 3. Kerugian ditanggung sesuai dengan porsi dana masing-masing; } \\
\text { 4. }\end{array}$ \\
& BPRS dan nasabah masing-masing bertindak sebagai mitra usaha \\
\hline
\end{tabular}




\begin{tabular}{|l|l|}
\hline & $\begin{array}{l}\text { untuk membiayai kegiatan usaha tertentu yang tidak bertentangan } \\
\text { dengan prinsip syariah. }\end{array}$ \\
& $\begin{array}{l}\text { 5. Kesepakatan antara BPRS dengan nasabah dituangkan dalam } \\
\text { Akad Musyarakah. }\end{array}$ \\
\hline $\begin{array}{l}\text { Fatwa Nomor 07/DSN- } \\
\text { MUI/ 1V/2000 tentang } \\
\text { Pembagian Mudharabah }\end{array}$ & $\begin{array}{l}\text { 1. BPRS menyediakan dana sebagai pinjaman atau pembiayaan yang } \\
\text { diterima dari bank atau pihak ketiga bukan bank; }\end{array}$ \\
& $\begin{array}{l}\text { 2. } \begin{array}{l}\text { BPRS mengungkapkan rincian pinjaman/pembiayaan yang sebesar } \\
\text { nominal yang diterima; }\end{array} \\
\text { 3. Nasabah memberikan bagi hasil atas pinjaman/pembiayaan yang } \\
\text { diterima sesuai kesepakatan. }\end{array}$ \\
& $\begin{array}{l}\text { 4. Kesepakatan antara BPRS dengan nasabah dituangkan dalam } \\
\text { Akad Mudharabah. }\end{array}$ \\
\hline
\end{tabular}

D-1.3 Akad Sewa, Sewa Beli Dan Pengurusan Jasa (Ijarah, Ijarah Muntahiya

Bit Tamlik, Ijarah Multi Jasa)

\begin{tabular}{|c|c|}
\hline FATWA DSN-MUI & PENERAPAN AKAD PEMBIAYAAN \\
\hline $\begin{array}{l}\text { Fatwa Nomor 09/DSN- } \\
\text { MUI/1V/2000 tentang } \\
\text { Pembiayaan ljarah }\end{array}$ & $\begin{array}{l}\text { 1. BPRS menyediakan dana dalam rangka pemindahan hak guna } \\
\text { atau manfaat atas suatu aset; } \\
\text { 2. BPRS melakukan ini dalam waktu tertentu dengan pembayaran } \\
\text { sewa (ujrah) tanpa diikuti dengan pemindahan kepemilikan aset; } \\
\text { 3. BPRS sebagai pemilik dan/atau pihak yang mempunyai hak } \\
\text { penguasaan atas barang sewa baik berupa barang atau jasa; } \\
\text { 4. BPRS menyewakan barang atau jasa dimaksud kepada nasabah } \\
\text { sesuai kesepakatan; } \\
\text { 5. Kesepakatan antara BPRS dengan nasabah dituangkan dalam } \\
\text { Akad Pembiayaan ljarah. }\end{array}$ \\
\hline $\begin{array}{l}\text { Fatwa Nomor 27/DSN- } \\
\text { MUI/III/2002 tentang Al- } \\
\text { ljarah Al-Muntahiyah Bi Al- } \\
\text { Tamlik }\end{array}$ & $\begin{array}{l}\text { 1. BPRS menyediakan dana untuk memindahkan hak guna atau } \\
\text { manfaat dari suatu barang atau jasa; } \\
\text { 2. BPRS melaksanakan ini berdasarkan transaksi sewa dengan opsi } \\
\text { pemindahan kepemilikan barang; } \\
\text { 3. BPRS menyediakan dana dalam kegiatan ijarah dengan nasabah; } \\
\text { 4. BPRS dapat bertindak sebagai pembeli janji (wa`ad) antara lain } \\
\text { untuk memberikan opsi pengalihan hak kepemilikan barang sewa } \\
\text { kepada nasabah sesuai kesepakatan; } \\
\text { 5. Kesepakatan antara BPRS dengan nasabah dituangkan dalam } \\
\text { Akad Al-ljarah Al-Muntahiyah bi At-Tamlik. }\end{array}$ \\
\hline
\end{tabular}

D-1.4 Akad Pinjaman Beragunan Emas (Rahn)-Gadai Emas

\begin{tabular}{|l|c|}
\hline \multicolumn{1}{|c|}{ FATWA DSN-MUI } & \multicolumn{1}{c|}{ PENERAPAN AKAD PEMBIAYAAN } \\
\hline Fatwa Nomor 26/DSN- & 1. BPRS menyediakan dana qardh dengan agunan berupa emas \\
MUI/ III/2002 tentang Rahn & \\
\hline
\end{tabular}




\begin{tabular}{|l|l|}
\hline Emas & \multicolumn{1}{|l|}{ yang diikat dengan akad rahn; } \\
& $\begin{array}{l}\text { 2. BPRS menyimpan dan memelihara emas yang diagunkan selama } \\
\text { jangka waktu tertentu; }\end{array}$ \\
& $\begin{array}{l}\text { 3. Nasabah yang mengagunkan emas membayar biaya penyimpanan } \\
\text { dan pemeliharaan atas emas sebagai objek rahn. } \\
\text { 4. Kesepakatan antara BPRS dengan nasabah dituangkan dalam } \\
\text { Akad Rahn. }\end{array}$ \\
\hline Fatwa Nomor 25/DSN- & $\begin{array}{l}\text { 1. BPRS menyediakan dana qardh dengan agunan berupa emas } \\
\text { MUI/ III/2002 tentang Rahn diikat dengan akad rahn; }\end{array}$ \\
& $\begin{array}{l}\text { 2. BPRS menyimpan dan memelihara emas yang diagunkan selama } \\
\text { jangka waktu tertentu; }\end{array}$ \\
& $\begin{array}{l}\text { 3. Nasabah yang mengagunkan emas membayar biaya penyimpanan } \\
\text { dan pemeliharaan atas emas sebagai objek rahn. } \\
\text { 4. Kesepakatan antara BPRS dengan nasabah dituangkan dalam } \\
\text { Akad Rahn. }\end{array}$ \\
\hline
\end{tabular}

D-1.5 Akad Pinjaman Kebajikan (Qardhul Hasan)

\begin{tabular}{|c|c|}
\hline FATWA DSN-MUI & PENERAPAN AKAD PEMBIAYAAN \\
\hline $\begin{array}{l}\text { Fatwa Nomor 19/DSN- } \\
\text { MUI/IV/2001 Tentang } \\
\text { Qardh Hasan }\end{array}$ & $\begin{array}{l}\text { 1. BPRS menyedikan dana atau tagihan berdasarkan persetujuan } \\
\text { atau kesepakatan dengan nasabah; } \\
\text { 2. Nasabah diwajibkan melunasi pinjamannya setelah jangka waktu } \\
\text { tertentu sesuai kesepakatan; } \\
\text { 3. BPRS memberi pinjaman qardh kepada nasabah berdasarkan } \\
\text { kesepakatan yang tidak mempersyaratkan adanya imbalan kecuali } \\
\text { biaya administrasi; } \\
\text { 4. BPRS memberikan pinjaman kepada nasabah dengan } \\
\text { menggunakan dana infaq, sodaqah, dan zakat. } \\
\text { 5. Kesepakatan antara BPRS dengan nasabah dituangkan dalam } \\
\text { Akad Qardh Hasan }\end{array}$ \\
\hline
\end{tabular}

D-1.6 Akad Pinjaman Talangan dan Talangan Haji (Qardh)

\begin{tabular}{|l|rl|}
\hline \multicolumn{1}{|c|}{ FATWA DSN-MUI } & \multicolumn{1}{c|}{ PENERAPAN AKAD PEMBIAYAAN } \\
\hline Fatwa Nomor 29/DSN- & 1. & $\begin{array}{l}\text { BPRS menyedikan dana atau tagihan berdasarkan persetujuan } \\
\text { MUI/ 1V/2002 tentang }\end{array}$ \\
$\begin{array}{l}\text { Pembiayaan Pengurusan } \\
\text { Haji Lembaga Keuangan } \\
\text { Syari'ah }\end{array}$ & $\begin{array}{l}\text { 2. } \begin{array}{l}\text { Nasabah diwajibkan melunasi pinjamannya setelah jangka waktu } \\
\text { tertentu (sebelum pergi haji) sesuai kesepakatan dengan margin } \\
\text { yang disepakati; }\end{array} \\
\text { 3esepakatan antara BPRS dengan nasabah dituangkan dalam } \\
\text { Akad Qardh }\end{array}$ \\
\hline
\end{tabular}

Sumber: Fatwa DSN-MUI dan SEOJK 
Berdasarkan keterangan dari pihak BPRS Amanah Ummah yang disampaikan oleh Drs.H.M. Abduh Khalid M, M.Si dan Hendi Sofyan, BBA. Bahwa dari beberapa produk-produk pembiayaan syariah yang disediakan oleh BPRS seperti tersebut pada tabel itu ternyata lebih dari $90 \%$ masyarakat yang menjadi nasabah memilih produk pembiayaan dengan transaksi jual-beli (akad murabahah). Fenomena ini menunjukkan bahwa masyarakat yang menjadi nasabah BPRS Amanah Ummah bergerak disektor riil perdagangan atau kebutuhan sekunder lainnya seperti membangun dan memperbaiki rumah tempat tinggal dan sebagainya yang dikategorikan akad murabahah.

Sebagai salah satu contoh pembiayaan murabahah seperti ditetapkan dalam fatwa DSN-MUI Nomor 04/DSN-MUI/ IV/2000 tentang Murabahah dan SEOJK Nomor 37/SEOJK.03/2015 tentang Produk dan Aktivitas Bank Pembiayaan Rakyat Syariah itu mengatur akad dan transaksi jual-beli. Dalam hal ini pihak BPRS Amanah Ummah menerapkan prosedur akad murabahah dengan cara: (1) BPRS menyediakan dana atau tagihan untuk transaksi jual beli barang sebesar harga pokok; (2) Margin berdasarkan persetujuan atau kesepakatan antara BPRS dengan nasabah; (3) Nasabah melunasi pinjaman sebagai kewajibannya dalam jangka waktu tertentu; (4) BPRS menyediakan dana untuk membelikan barang; (5) Nasabah membeli barang sesuai yang diinginkan; dan (6) Kesepakatan antara BPRS dengan nasabah dituangkan dalam Akad Murabahah.

Dalam penerapan produk-produk pembiayaan syariah BPRS selain murabahah dilakukan dengan prosedur yang sesuai dengan Fatwa DSN-MUI dan SEOJK supaya tidak terlepas kesyariahannya. Konsistensi dalam penerapan Fatwa DSN-MUI dan SEOJK inilah yang menjadikan BPRS Amanah Ummah mendapat penilaian positif saat disupervisi secara langsung oleh pihak OJK dengan meneliti dokumen-dokumen akad dan bukti-bukti transaksi antara BPRS Amanah Ummah dengan nasabah.

\section{Kriteria BPRS Amanah Ummah sebagai BPRS Unggul di Indonesia}

BPRS Amanah Ummah yang berlokasi di Leuwiliang, Kabupaten Bogor sebagai salah satu BPRS unggul di Indonesia dalam mempromosikan produk-produk perbankannya dengan penerapan prinsip-prinsip syariah. BPRS Amanah Ummah dapat melanjutkan warisan perjuangan dari KH. Sholeh Iskandar sehingga kini berhasil menorehkan prestasi dan mencapai kinerja perbankan sangat baik. Menurut Hendi Sofyan, BBA. Kepala BPRS Amanah Ummah Kantor Cabang Bogor menyatakan bahwa perolehan tabungan yang sangat signifikan itu dilatarbelakangi oleh pelayanan yang sangat memuaskan bagi nasabah.

Berdasarkan laporan dari Infobank dinyatakan tentang keunggulan BPRS Amanah Ummah dibanding dengan enam BPRS lainnya yang sekelas dengan indikator aset kisaran Rp100 Miliar s.d. di bawah Rp250 Miliar. BPRS Amanah Ummah telah membukukan aset modal perbankan pada 2017 mencapai Rp242.03 Miliar. Sementara BPRS lainnya seperti BPRS Patriot Bekasi Rp144.00 Miliar, BPRS Kotabumi Rp154.63 Miliar, BPRS Suriyah Rp158.03 Miliar, BPRS Lantabur Tebuireng Rp.124.03 
Miliar, BPRS Buana Mitra Perwira Rp107.48 Miliar, dan BPRS Sukowati Sragen Rp180.03 Miliar. ${ }^{13}$

Keunggulan lainnya BPRS Amanah Ummah dalam transaksi akad ini juga mendapat penilaian sangat baik (prudent) dari pihak pihak OJK karena dapat menekan biaya-biaya administrasi dengan cara realcost, bukan prosentase dari pembiayaan. Selain itu margin keuntungan kisaran tidak lebih dari 1\%, pemberian discount jika nasabah melunasi lebih cepat dari waktu yang telah disepakati dalam akad; dan juga tersedianya layanan pickup services dengan cara menjemput tabungan secara langsung dari nasabah oleh petugas sehingga nasabah tidak harus datang ke BPRS Amanah Ummah untuk menyetorkan tabungan/pelunasan pembiayaan.

Berpijak pada operasional yang meliputi unsur penghimpunan dana, pembiayaan, dan pelayanan jasa bank maka BPRS Amanah Ummah mendapat berbagai penghargaan antara lain dari: (1) Karim Consulting Indonesia sebagai $1^{\text {st }}$ Rank Prudent Islamic Rural Bank, Java Region (2014), dan (2) Majalah Info Bank sebagai BPRS terbaik Nomor 1 (satu) di tingkat nasional dalam kategori aset BPRS di atas Rp100 miliar (2015); dan (3) Majalah Info Bank menganugerahkan Golden Award sebagai BPRS yang memiliki kinerja terbaik salama lima tahun berturut turut. ${ }^{14}$

\section{KESIMPULAN}

Hasil penelitian dapat disimpulkan: (1) hasil evaluasi dari OJK bahwa BPRS Amanah Ummah dalam pelayanan produk-produk perbankan khususnya pada produk pembiayaan dapat menerapkan prinsip-prinsip syariah sesuai dengan Fatwa DSN-MUI yang telah dilegalisasi dalam SEOJK; dan (2) hasil penilaian dari pihak lembaga profesional perbankan (Infobank) bahwa kriteria keunggulan BPRS Amanah Ummah dalam beberapa hal: (a) aset modal di atas Rp100 Milyar, (b) konsistensi penerapan Fatwa DSN-MUI dengan biaya administrasi realcost, (c) margin keuntungan tidak lebih dari 1\%, (d) pemberian discount bagi nasabah yang melunasi lebih cepat, dan (e) layanan pickup services dengan cara antra/jemput tabungan/pelunasan dari/untuk nasabah secara langsung oleh petugas BPRS.

Berdasarkan hasil penelitian tersebut direkomendasikan bahwa BPRS Amanah Ummah harus terus berusaha menerapkan Fatwa DSN-MUI terutama yang telah mendapat legalisasi dari OJK dalam semua skema penghimpunan dana, produk pembiayaan syariah, dan pelayanan jasa yang sejalan dengan syariah. BPRS Amanah Ummah dapat menjadi rujukan bagi BPRS lainnya sehingga mendapat kepercayaan dari masyarakat, akademisi, profesional, pemerhati dan pihak otoritas perbankan di Indonesia.

Penelitian terhadap keunggulan BPRS Amanah Ummah, dilaksanakan atas dana hibah penelitian tahun 2019/2020 Sekolah Pascasarjana Universitas Pakuan

${ }^{13}$ InfoBank. 2018. Babak Akhir Bank Muamalat, Jakarta, Majalah Infobank Institute, Edisi Khusus Syariah, hlm. 54 .

${ }^{14}$ InfoBank. 2018. Babak Akhir Bank Muamalat, Jakarta, Majalah Infobank Institute, Edisi Khusus Syariah, hlm. 66. 
berdasarkan surat Nomor 144/SPs/Unpak/II/2020 tanggal 11 Februari 2020. Dengan selesainya penelitian ini, tim peneliti dari program Pascasarjana Magister Ilmu Hukum mengucapkan terima kasih kepada Rektor, para wakil Rektor, dan Direktur Pascasarjana Universitas Pakuan. Ucapan terima kasih juga disampaikan kepada pihak BPRS Amanah Ummah yang bersedia sebagai narasumber/informan penelitian untuk melengkapi informasi dan klarifikasi atas data dan fakta yang disajikan dalam pelaporan penelitian ini.

\section{E. REFERENSI}

Amin, KH. Ma`ruf. 2002. Fatwa dalam Sistem Hukum Islam, Jakarta, elSAS.

Alamsyah, Indra Fajar. 2013. Penggunaan Produk Perbankan Syariah Yang Menggunakan Akad Wadiah Dihubungkan Dengan Fiqih Muamalah, JURNAL SCIENTICA, UNIBAS, Vol. 1 No.2, Desember 2013, No. ISSN: 2407-2001.

Ali, Zainuddin. 2008. Hukum Ekonomi Syariah, Jakarta, Sinar Grafika.

Antonio, Muhammad Syafi'i. 2001. Bank Syariah Dari Teori Ke Praktik, Jakarta, Gema Insani.

Bank Indonesia. 2016. Perjalanan Perbankan Syariah di Indonesia, Jakarta, Departemen Riset Kebanksentralan Bank Indonesia.

BPRS Amanah Ummah. 2019. Melanjutkan Warisan Perjuangan K.H. Sholeh Iskandar (alm), Bogor, Brosur PT. BPRS Amanah Ummah.

Hermansyah. 2014. Hukum Perbankan Nasional Indonesia, Jakarta, Prenada Media Group.

Hartini, Sri. 2018. Otoritas Jasa Keuangan dalam Pengaturan \& Pengawasan Perbankan Syariah Berbasis Fatwa Dewan Syariah Nasional, Bogor, UIKA Press.

Majelis Ulama Indonesia. 2006. Himpunan Fatwa Dewan Syariah Nasional MUI, Jakarta, DSN-MUI dan BI.

Rosyadi, A. Rahmat. 2006. Formalisasi Syariat Islam dalam Perspektif Tata Hukum Indonesia, Jakarta, Ghalia Indonesia.

Hartini, Sri. 2019. Otoritas Jasa Keuangan: Pengaturan \& Pengawasan dalam Perbankan Syariah Berbasis Fatwa Dewan Syariah Nasional, Bogor: UIKA PRESS.

Sutedi, Adrian. 2014. Aspek Hukum Otoritas Jasa Keuangan, Jakarta, Raih Asah Sukses.

Usman, Rahmadi. 2013. Produk dan Akad Perbankan Syariah di Indonesia: Implementasi dan Aspek Hukum, Bandung, Citra Aditia.

InfoBank. 2018. Babak Akhir Bank Muamalat, Jakarta, Majalah Infobank Institute, Edisi Khusus Syariah. 